\title{
AS FORMAS PRONOMINAIS TU, VOCÊ E O(A) SENHOR(A) NO PORTUGUÊS FALADO EM CAMETÁ - ESTADO DO PARÁ, EM UMA ABORDAGEM SOCIOFUNCIONALISTA
}

Raquel Maria da Silva Costa (UFPA)

Resumo: Este trabalho apresenta um estudo sobre a alternância das formas pronominais de referência à segunda pessoa, Tu/Você/o(a) Senhor(a), na função de sujeito, no português falado na zona urbana de Cametá/PA. Adota a interface entre a Teoria da Variação e Mudança Linguística e o Funcionalismo linguístico, gerando dessa forma uma abordagem caracterizada no âmbito dos estudos linguísticos de sociofuncionalista. Objetiva analisar o papel de fatores linguísticos e extralinguísticos ou sociais como motivadores do comportamento variável de tu/você/o(a) senhor(a) em função de sujeito. O corpus contém dados de interações face a face de 16 grupos focais, cada qual constituído por 04 sujeitos participantes, sendo um o informante-base, todos cametaenses, estratificados de acordo com a faixa etária (21 a 29 anos e 32 a 42 anos), o sexo/gênero e o nível de escolaridade (médio e superior), totalizando 64 participantes. Na fala dos 16 informantesbase, obtivemos 527 dados de uso de Tu, Você e o(a) Senhor(a), os quais foram analisados quantitativamente e qualitativamente. Os resultados apontaram 307 ocorrências da forma pronominal tu, 182 de você e apenas 38 da forma o(a) senhor(a), o que corresponde, respectivamente, a $58.3 \%$, 34.5\% e $7.2 \%$. No âmbito do Sociofuncionalismo, ao avaliarmos a correlação entre variável dependente e variáveis independentes pelo princípio da marcação, verificamos que a forma tu é menos marcada na linguagem cametaense, considerando-se a distribuição de frequência e a complexidade estrutural. A forma você, de menor frequência e maior complexidade estrutural e cognitiva, por isso mais marcada, encontra predileção, nos contextos mais marcados.

Palavras-chave: Pronomes de referência à segunda pessoa; Variação linguística; Princípio da marcação.

Abstract: This article presents a study of the alternation of pronominal forms of reference to the second person, Tu/Você/o(a) Senhor(a), in 
the subject function, in the Portuguese spoken in the urban area of Cametá. It adopts, as a theoretical framework, the interface between two postulates: Linguistic Variation and Change Theory and Linguistic Functionalism, generating a featured approach within the language studies of social functionalist. Our research intends to analyze the role of linguistic factors and of extralinguistic or social factors as motivators of the variable behavior of tu/você/o(a) senhor(a) in the subject function. The corpus contains data of face to face interaction of 16 focus groups, each one constituted by 04 (four) participant individuals, with one being the basis informant, all born in Cametá, stratified by age (21-29 years old and 32-42 years old), gender (male and female) and level of education (high school and higher education), totalizing 64 participants. By the basis informants speech, we got 527 data uses of Tu, Você e o(a) Senhor(a), which were quantitatively and qualitatively analyzed. The results pointed 307 occurrences of the pronominal form $t u, 182$ of voce and only 38 of $o(a)$ senhor(a), which represents, respectively, $58.3 \%, 34.5 \%$, e $7.2 \%$. Within the Social functionalism, evaluating the correlation between dependent variable and independent variables by the principle of marking, we noted that the form tu is less marked in the language of Cametá, considering the distribution of frequency and structural complexity. The form você, that presents less frequency and greater structural and cognitive complexity, hence more marked, finds predilection, in more marked contexts.

Keywords: Pronouns of reference to the second person; Linguistic variation; Principle of marking.

\section{INTRODUÇÃO}

O Português Brasileiro (doravante PB) possui um pronome pessoal do caso reto de segunda pessoa tu, usado para se referir à pessoa com quem se fala, porém se observa, em algumas regiões do Brasil, com base em trabalhos já realizados sobre este pronome, como os de Andrade (2004) ${ }^{1}$, Santos (2010)²,

\footnotetext{
1 Pesquisa sobre o uso de você/cê/tu na Vila de Planalto (DF).

2 Pesquisa sobre o tu/você no Centro urbano da cidade de Rio de Janeiro (RJ).
} 
Modesto (2006) 3 , Oliveira (2007) ${ }^{4}$, Alves (2011) ${ }^{5}$, Herênio $(2006)^{6}$, que ele está cedendo espaço na fala para o pronome de tratamento você, passando este a ganhar valor de pronome pessoal e constituindo-se um dos elementos linguísticos mais recorrentes para se dirigir a qualquer pessoa.

Em função disso, surge o interesse em investigar este fenômeno em variação na língua de uso cotidiano dos falantes cametaenses, para verificar até que ponto fatores sociais como relações interacionais hierárquicas (simétricas e assimétricas) e fatores linguísticos como: referência do pronome (genérica e específica), paralelismo, tipo de discurso e tipo de frase podem condicionar o uso alternado entre $t u$, você e o(a) senhor(a).

Para alcançarmos tal objetivo, conjugamos duas bases teóricas da linguística: a Teoria da Variação e Mudança linguística e o Funcionalismo. À luz da Teoria da Variação, que considera o estudo da língua em seu contexto sociocultural dentro de uma comunidade de fala, pretendemos compreender a variação das formas de referência à segunda pessoa, através da combinação da estrutura social, pela

\footnotetext{
3 Pesquisa sobre tu/você na cidade de Santos (SP).

4 Pesquisa sobre a variação do tu/você nas comunidades rurais de Santo Antônio de Jesus e Poções (BA).

5 Pesquisa realizada sobre o tu/você nos municípios de São Luís e Pinheiro (Mesorregião Norte), Bacabal e Tuntum (Mesorregião Centro) e Alto Parnaíba e Balsas (Mesorregião Sul) (MA).

6 Pesquisa sobre tu/você nos estados de Uberlândia (MG) e Imperatriz (MA).
} 
observação das variáveis sexo/gênero, nível de escolaridade e faixa etária, à estrutura linguística, na possibilidade de depreendermos e sistematizarmos o caminho desta variação na língua falada. Associado à interferência das variáveis sociais neste estudo, acrescentaremos também a análise da interferência dos diferentes estilos linguísticos, no uso alternado das formas Tu, Você e o(a) Senhor(a), motivados pelo contexto de fala.

Para a análise da influência de tais fatores linguísticos e sociais sobre a variável linguística aqui estudada, pretendemos, como objetivos: 1. Investigar se o pronome tu é favorecido quando usado em referência a um locutor específico, e o pronome você quando utilizado em referência genérica; Observar se a codificação explícita precedente dos pronomes tu, você e o(a) senhor(a) favorece a codificação destas mesmas formas sequencialmente na sentença, gerando assim a manutenção de $t u$, você e ou o(a) senhor(a) na cadeia da fala; Examinar qual o tipo de discurso, fala própria, relatado do próprio falante ou relatado de terceira pessoa que mais pode favorecer o uso das formas tu, você e o(a) senhor(a) na fala da comunidade investigada; Analisar se o tipo de frase, afirmativa, interrogativa, negativa e exclamativa, constitui-se um fator motivador da escolha entre uma das formas de segunda pessoa tu, você e o(a) 
senhor(a); Investigar o uso das formas o(a) senhor (a), tu e você nas relações interacionais simétricas e assimétricas, levando em consideração se o fator proximidade/intimidade e distância social/ relação não íntima contribuem para a escolha desses pronomes na fala dos cametaenses da zona urbana.

Assim, este trabalho compõe-se de 3 itens, além da introdução e das considerações finais. No primeiro item, se estabelece uma interface teórico-metodológica entre a Sociolinguística laboviana/variacionista (WEINREICH; LABOV; HERZOG, 2006) e os princípios do funcionalismo (GIVÓN, 1995), sob a denominação de Sociofuncionalismo. Posterior a isso, no segundo item, apresentaremos a orientação teóricometodológica da Sociolinguística quantitativa que subsidiará a coleta e tratamento dos dados, no programa estatístico GOLDVARB. Por fim, exporemos a descrição e a análise dos resultados sobre as formas pronominais de referência à segunda pessoa, na função sintática de sujeito da oração: tu, você e o(a) senhor(a), no Português falado na zona urbana do município de Cametá (PA).

\section{ABORDAGEM TEÓRICA: UMA INTERFACE ENTRE TEORIAS}

Este item estabelecerá uma interface teórico-metodológica entre a Sociolinguística laboviana/variacionista (WEINREICH; 
LABOV; HERZOG, 2006) e os princípios do Funcionalismo (GIVÓN, 1995), voltados para uma visão funcional da variação na língua, com o intuito de associar a procedência da alternância das formas de referência à segunda pessoa em estudo a motivações externas à estrutura da língua, oriundas das diferentes intenções comunicativas.

\subsection{A Sociolinguística Variacionista}

Os estudos sociolinguísticos são ampliados pelos trabalhos desenvolvidos por Labov na década de 70. Na tentativa de sistematizar a variação e descobrir os padrões que a regem, o autor encontrou a solução para o dito problema através da estratificação social e avaliação social das variantes linguísticas, tanto no estudo sobre a centralização dos ditongos (ay) e (aw) na comunidade de fala da ilha de Martha's Vineyard ([1962], 1963), no estado de Massachusetts (EUA), quanto no estudo sobre a estratificação do /r/ na cidade de Nova lorque (1966), em lojas de departamento, sob a orientação de Weinreich.

Dessa forma, a Sociolinguística inova os trabalhos desenvolvidos pelas tendências linguísticas anteriores na medida em que apresenta a língua como um sistema heterogêneo, em que o falante pode lançar mão de diferentes formas linguísticas para se expressar, e a opção 
por uma variante, em detrimento de outra, não ocorre de forma aleatória, mas condicionada tanto por fatores de ordem social como linguísticos.

A língua, assim, passa a ser compreendida como um sistema dinâmico, em que a fala é o seu mecanismo de mudança. O objeto de estudo da sociolinguística é, portanto, a própria diversidade linguística. E, assim, a fala tornase a principal fonte de riqueza e pesquisa para os estudos sociolinguísticos. A língua falada deve ser descrita, analisada e documentada em seu uso real, no seio da comunidade de fala da qual faz parte. Tal comunidade é constituída, por conseguinte, de sujeitos falantes que dominam o mesmo conjunto de regras linguísticas e interagem entre si por meio de uma teia comunicativa.

O ambiente social em que o sujeito falante encontra-se inserido será um fator decisivo nessa escolha, assim como as relações sociais que os falantes estabelecem entre si, como no caso das formas pronominais em estudo. Para Labov (1982), a heterogeneidade é parte íntegra da economia linguística de uma comunidade, necessária para satisfazer as demandas linguísticas da vida cotidiana.

Weinreich, Labov e Herzog (2006) pressupõem que a variação existente na forma atual de uma dada língua (sincrônica) representa o desenvolvimento diacrônico que esta língua 
vem atravessando no decorrer dos tempos, tendo-se assim a coexistência de diferentes estágios de uma mesma língua num dado momento da história. É seguindo este pressuposto que nos empenhamos em analisar os fatores condicionantes do fenômeno em estudo.

Para Labov (2004), a análise da variação envolve primeiro a observação da variação, isto é, que "há duas formas alternativas de dizer a mesma coisa"7 e depois a "procura pelo ambiente mais recorrente em que esta variação ocorra, a fim de aplicar o princípio de contabilidade 8 " (LABOV, 2004, p.03 - tradução nossa). A definição assim de uma variável linguística requer o estabelecimento de um conjunto fechado de fatores linguísticos e não linguísticos, ao qual se aplicam os axiomas da teoria da probabilidade. Então, a principal tarefa é encontrar e definir as variáveis independentes que serão incluídas no estudo. Labov (2004) afirma que tais parâmetros em análises sociolinguísticas podem levar a resultados bastante interessantes acerca do fenômeno em estudo.

\subsection{Funcionalismo}

O Funcionalismo é uma teoria que leva em consideração as relações estabelecidas entre as unidades linguísticas e as

\footnotetext{
7 No original: "That there are two alternative ways of saying the same thing".

8 No original: "variation searches for the largest environment in which this variation occurs, in order to apply the principle of accountability."
} 
funções que estas exercem nas interações, compreendendo a gramática de uma língua como um sistema acessível e organizado de acordo com as pressões do uso. Para Neves (1997), uma gramática funcional considera a competência comunicativa do falante, isto é, a capacidade que este possui de não apenas codificar e decodificar expressões, mas também de usar e interpretar essas expressões de uma maneira interacionalmente satisfatória.

Assim, o Funcionalismo constitui-se como uma teoria que se liga, acima de tudo, aos fins a que servem as unidades linguísticas, o que significa dizer que ele se ocupa exatamente das funções dos meios linguísticos de expressão (NEVES, 1997). Logo, a língua é um "sistema funcional" (FONTAINE, 1978), orientada sempre para um determinado fim. É consequentemente um sistema de meios de expressão adequados a um dado objetivo, isto é, uma intenção comunicativa.

Neste trabalho, o termo "funcionalismo" será compreendido como aquele que concebe a língua como instrumento de comunicação e interação social entre os seres humanos, e essa língua como tal não pode ser "analisada como um objeto autônomo, mas como uma estrutura maleável, sujeita a pressões oriundas das diferentes situações comunicativas, que ajudam a determinar sua estrutura gramatical" (CUNHA; OLIVEIRA; MARTELLOTA, 2003, p.20). 
Essa compreensão da gramática baseia-se nos princípios teóricos de Givón (1995), que acredita que fatores discursivos, sociais, culturais, cognitivos, históricos, comunicativos, mudança e variação podem influenciar na forma de se codificar a informação gramatical. Portanto, é a situação comunicativa na qual o falante está inserido que condiciona, restringe, explica, e até mesmo determina a estrutura gramatical. Então, se a língua varia é porque os inúmeros fatores que influenciam o seu uso variam também, pois, para cumprir propósitos mais gerais, de que nem sempre se tem consciência, o sistema linguístico tem natureza adaptativa, pois é sensível às pressões do uso (GIVÓN, 2001). É a gramática moldando o discurso e este moldando a gramática.

E é por esse viés de análise que as contribuições teóricas do funcionalismo serão consideradas neste trabalho. Na medida em que também se olhará para fora do sistema linguístico, buscando explicações comunicativo-funcionais que possam justificar o uso alternado das formas de referência à segunda pessoa na comunidade em estudo. Para Givón (1995), a gramática está emergindo e mudando dentro do próprio discurso e sob a influência dos seus elementos contextuais.

É neste processo comunicativo, pois, que a língua é adquirida e a gramática emerge e muda. A forma ajusta-se, criativamente e estimulada pelo contexto, para 
novas funções e novos significados. A variação e a indeterminação são partes necessárias para o mecanismo que modela e remodela a competência. Assim, o uso de uma ou de outra forma variante se daria segundo o modo como o falante precisa apresentar a informação para o seu ouvinte, levando em conta, principalmente a natureza da situação comunicativa. Além disso, essa abordagem funcionalista, a partir de funções cognitivo-comunicativas de significação lexical e semânticoproposicional, abre portas também à incorporação de hipóteses funcionalistas como extensão da análise variacionista a fenômenos discursivos. (REIS, 2003, p.76)

E se a gramática surge em função do uso, para o modelo funcionalista, ela sempre estará oscilante, nunca estabilizada, já que as intenções comunicativas sempre serão diversas. Logo a língua receberá sempre motivações diferentes, tendo, portanto, a forma atualizações constantes em decorrência da função dada a ela pelo falante. Por isso que linguistas, segundo Cunha, Oliveira e Martellota (2003), como Hopper (1991) e Givón (1995), passaram a defender uma linguística baseada no uso, cuja tendência principal é observar a língua do ponto de vista do contexto linguístico e da situação extralinguística, partindo da função para buscar compreender a forma no ato comunicativo e não depreender a forma para em seguida procurar explicações das diferentes funções que esta possa exercer. 
Givón (1995) estabelece um conjunto de premissas, contextualmente definidas, para caracterizar a visão funcionalista da linguagem, tais como: a linguagem é uma atividade sociocultural; a estrutura serve a funções cognitivas ou comunicativas; a estrutura é não-arbitrária, e sim motivada, icônica; a mudança e variação estão sempre presentes na língua; o sentido é contextualmente dependente e não-atômico; as categorias gramaticais não são formadas pelas relações discretas de suas unidades, mas sim escalares, gradativas e relativamente contextuais; a estrutura é maleável e não-rígida; as gramáticas são emergentes; as regras da gramática permitem algumas exceções/vazamentos.

Tais pressupostos pautam dois princípios básicos defendidos pelo Funcionalismo givoniano, o princípio de iconicidade e o princípio de marcação. Iconicidade ou motivação funcional refere-se à correlação transparente entre forma e função, isto é, a estrutura que a língua manifesta na superfície reflete as funções semânticas e pragmáticas que a ela correspondem, assim como a forma gramatical correlaciona-se com a função semântica ou pragmática em uma maneira não-arbitrária ("icônica"). Este princípio givoniano concebe que a forma linguística (expressão), explicitada em uma dada proposição, seja 
reflexo da intenção comunicativa (conteúdo/significado) de quem a produz, o que consequentemente impulsiona as escolhas lexicais e gramaticais realizadas pelo falante.

Porém, para Givón (1995), esse princípio não deve ser concebido de forma idealizada em uma correlação biunívoca de um para um entre forma e significado (interpretação semântico-pragmática) e sim deve-se esperar um viés sistemático no código linguístico em direção a uma conversão de um para muitos da forma ao significado, e de muitos para um do significado para a forma. No caso de uma única forma para muitos significados, o autor exemplifica com ambiguidade e polissemia (uma forma - sintática ou lexical - adquire mais de uma função), que são cada vez mais recorrentes na gramática de uma língua. Quanto a um significado ser representado por diferentes formas, considera-se variação linguística.

O princípio de iconicidade é uma crítica de Givón (1995) a um dos três dogmas ${ }^{9}$ centrais de Saussure, a doutrina da arbitrariedade do signo linguístico. Givón entende que o sistema comunicativo de uma língua é orientado iconicamente pelo sistema de representação cognitiva. A este princípio, Givón

9 O segundo dogma de Saussure refere-se à idealização associada à distinção fiel entre langue e parole, que para Givón (1995) pode ser vista como uma manobra puramente metodológica. O terceiro dogma de Saussure refere- se a uma estrita separação entre a descrição diacrônica e sincrônica da língua. 
(2001) estabelece três subprincípios: princípio da quantidade, princípio da proximidade ou adjacência eo princípio da ordenação linear. Tais princípios constroem a gramática, segundo o autor, e correlacionam-se às estruturas convencionais da língua.

O subprincípio da quantidade concebe a ideia de que há uma relação proporcional entre a quantidade de informações expressas em um texto e o tamanho que este adquirirá. O subprincípio da proximidade prediz que a ordenação do conteúdo proposicional na sentença considerando a relação espaço-temporal é iconicamente motivado pela proximidade cognitiva dos conteúdos. O subprincípio da ordenação linear refere-se à organização da informação na cadeia predicativa de uma oração de acordo com o grau de importância e a ordem de temporalidade dos fatos ou estado de coisas descritos.

A marcação refere-se à relação proporcional existente entre a noção de complexidade estrutural e complexidade cognitiva. O princípio de marcação, de acordo com Givón (1991), é contextualmente definido, assim, se em um dado contexto houver certas categorias de maior exigência cognitiva, a estrutura linguística de manifestação da proposição tenderá a ser estruturalmente mais complexa, isto é, marcada. Este princípio de marcação deriva da ideia de que as formas marcadas na língua são estruturalmente mais 
complexas do que as não-marcadas, que são mais usuais, corriqueiras e sem alto grau de complexidade e novidade para o discurso. Segundo Givón (1990, p.947) são três os critérios utilizados na distinção entre categoria marcada/ não-marcada, desmembrados nos subprincípios:

a) a complexidade estrutural prevê que a estrutura marcada tende a ser mais complexa, ou mais elaborada, que a não marcada; b) a distribuição de frequência ${ }^{10}$ preconiza que a categoria marcada é menos frequente que a não-marcada; c) a complexidade cognitiva refere-se ao fato de que a categoria marcada atua em contextos cognitivos mais complexos, por isso requer e exige também maior atenção e tempo de processamento, consequentemente requer um maior esforço mental para sua depreensão. (p.947)

\subsection{0 sociofuncionalismo}

No Brasil, a interface teórico-metodológica entre a Sociolinguística Laboviana e o Funcionalismo vem recebendo a denominação de Sociofuncionalismo. Esta vertente de análise da língua, por sua vez, não constitui uma teoria, mas uma nova abordagem, voltada para os aspectos discursivos da variação.

10 No projeto biológico em geral e na neurologia em particular, o equilíbrio entre o processamento automatizado e assistido está fortemente enviesado em termos de frequência. Informação recorrente, frequente e previsível é eventualmente processada pelos canais automáticos e modulares, que são relativamente livres de contexto. Informações menos frequentes e menos previsíveis são processadas através dos canais mais conscientes e assistidos, que podem procurar relevância contextual. (GIVóN, 1995, p.13) 
Segundo May (2009), embora haja pontos conflitantes entre estes dois postulados teóricos - funcionalismo e sociolinguística - tal aproximação torna-se necessária, na medida em que uma perspectiva pode ampliar "os horizontes da outra, fazendo surgir uma terceira proposta, mais ampla, que nos oferece ainda mais ferramentas para que cerquemos nosso objeto satisfatoriamente" (MAY, 2009, p.70). Seria, portanto, injusto considerar que o estudo somente pelo viés da sociolinguística ou do funcionalismo não fosse capaz de abarcar a complexidade do objeto estudado, mas sim que o casamento desses dois estudos com pontos de vista ora convergentes ora divergentes só tem a enriquecer a análise do estudo pretendido.

E apesar da existência de princípios teóricos divergentes entre a Sociolinguística variacionista e o Funcionalismo, no que diz respeito não só à definição do objeto de investigação científica (regras (in)variáveis versus motivações funcionais), mas ao método de análise, é possível a realização de pesquisas linguísticas que correlacionem e convirjam essas duas abordagens de análise da linguagem no estudo de um determinado fenômeno linguístico, como será o caso da pesquisa aqui desenvolvida sobre as formas de referência à segunda pessoa. 
Segundo Tavares (2003), tanto o Funcionalismo quanto a Sociolinguística tem como escopo de análise a língua em uso, cuja natureza heterogênea abriga a variação e a mudança; o corpus de estudo é constituído por situações reais de comunicação entre falantes que interagem entre si; a mudança linguística é vista como um processo contínuo e gradual, difundido ao longo do âmbito linguístico e do social, com alterações contínuas em termos de frequência; a língua é analisada a partir da complementariedade entre dados sincrônicos e diacrônicos; e "a maioria das inovações é passageira. Apenas algumas são repetidamente reutilizadas e, caso aceitas pela comunidade de fala, podem ser cada vez mais difundidas" (TAVARES, 2003, p.17-18).

No que diz respeito às diferenças existentes na forma de compreender o objeto analisado, Tavares (2003) aponta alguns aspectos dessemelhantes entre essas duas abordagens como: no funcionalismo, os aspectos fonológicos, morfológicos, sintáticos e semânticos são compreendidos como discursivos, uma vez que só ganham existência no discurso proferido; na sociolinguística, não há uma atribuição notória aos elementos constitutivos do discurso e/ou pragmáticos no escopo da análise.

Tanto no funcionalismo como na sociolinguística a frequência das ocorrências é um fator importante para o estudo da difusão linguística e social da mudança. Porém, para 
o funcionalismo, ela indica o estabelecimento e a manutenção da gramática, enquanto que, nos estudos sociolinguísticos, há uma necessidade de recorrência das formas para a análise e comparação através do instrumental estatístico. Quanto à relação entre os fenômenos linguísticos e a sociedade que usa a língua, no funcionalismo, de acordo com Tavares (2003, p. 117),

a) mudança espalha-se de forma gradual ao longo do espectro social; (b) costuma haver diferença entre falantes mais velhos e mais jovens, no caso de mudança em progresso; (c) forças sociais atuam no surgimento de inovações e em sua disseminação sociolinguística. Inspiração na sociolinguística variacionista para os itens (a) e (b), empregando seus conceitos e mesmo termos. Ampliação dos preceitos da sociolinguística no item (c).

A Sociolinguística comunga das mesmas concepções do funcionalismo quanto aos itens (a) e (b), dispostos acima, pois ela foi a vertente da Linguística, pioneira nos estudos dos aspectos sociais dos fenômenos de variação e mudança, principalmente em incorporar restrições sociais às regras variáveis (TAVARES, 2003).

Correlacionando os pontos em comum e os pontos divergentes entre as duas propostas expostas acima, obtém-se um novo campo de estudo, convergido dos princípios variacionistas e funcionalistas, sob o codinome de Sociofuncionalismo. 
Esta nova área é guiada pelos parâmetros de estudo linguísticos mais aprofundados e desenvolvidos tanto da sociolinguística como do funcionalismo. Há momentos em que a conversa na diferença entre estas vertentes linguísticas é mais consensual na convergência para o Sociofuncionalismo, como no trabalho voltado para a língua em uso, na análise de trechos reais de conversação entre sujeitos, na percepção da mudança como um ciclo ininterrupto e progressivo e na observação dos dados tanto no eixo sincrônico como diacrônico (adotando principalmente, do paradigma funcionalista, a observância do processo de gramaticalização em andamento, através das faixas etárias).

Há outros momentos em que o nível consensual do diálogo vai diminuindo, mas sem impedir, é claro, a existência deste. No caso, por exemplo, de análise das variáveis estruturais da língua (fonológicas, morfológicas, sintáticas e semânticas), - Sociofuncionalismo adota o contexto discursivo de suas realizações, para melhor compreender as motivações da variação e analisa a frequência de uso das ocorrências dessas variáveis como um fator fortalecedor para o estabelecimento e manutenção da gramática da língua, como também para averiguar os estágios de gramaticalização, princípios estes, todos advindos do Funcionalismo.

E para investigar com maior profundidade a relação entre língua e sociedade, o Sociofuncionalismo baseia-se nos 
estudos pioneiros da teoria da variação na associação de fatores sociais a regras variáveis, como também no tratamento empírico dos dados a partir de análise quantitativa operada sobre o valor estatístico de frequências e pesos relativos. Tais mecanismos são utilizados com o intuito de verificar os rumos da mudança na língua.

Convém aqui ressaltar o que Pires (1999) argumentou, ao referir-se a este casamento realizado na linguística: "o conhecimento se constrói na conversa na diferença, sem que com isto seja necessário supor um mesmo projeto em comum" (p.314). Poderíamos dizer que as diferenças existentes entre esses dois pontos de vista não eliminam a possibilidade de um diálogo pacífico e produtivo para a análise do objeto em estudo, assim como contribuições científicas significativas na área investigada poderão ser dadas.

Sendo assim, é possível postular a existência de variações entre as formas de tratamento do Português Brasileiro e, ao mesmo tempo, observar as restrições funcionais de alternância entre elas, pois embora constituam formas diferentes, na fala, para a referência ao mesmo estado de coisas, esta alternância entre as formas pode representar tarefas comunicativas distintas, intenções diferenciadas e práticas linguísticas diferenciadas. É por isso que, para Givón (1993), tais formas em variação estariam a serviço da forma como o falante, dependendo de sua intenção comunicativa, 
organiza a informação para o seu ouvinte, levando em conta o tipo de situação comunicativa, cujos pólos extremos e opostos são representados pela "formalidade e informalidade" dessa situação (p.264).

A crítica desenvolvida por Lavandera (1978) direciona-se ao fato de que é impossível, no campo da sintaxe, manter o conceito de variável sociolinguística como duas formas estruturalmente diferentes e opcionalmente disponíveis, significarem a mesma coisa, em um mesmo contexto comunicativo, pois em unidades morfológicas e sintáticas não há a manutenção do mesmo referente, haja vista que tais categorias gramaticais, já carregam por definição um significado referencial, diferente do ocorrido com os fonemas, que carregam consigo uma referência constante, conforme a autora. Esse é o caso deste trabalho que aborda sobre as formas de referência à segunda no PB, tu você e o(a) senhor(a). Embora convenha esclarecer aqui que acreditamos que podemos lidar sim com variáveis morfológicas, seguindo o conceito laboviano, porém a análise destas críticas tornase pertinente nesta pesquisa para compreendermos melhor o crescimento da proposta variacionista laboviana.

\section{PROCEDIMENTOS METODOLÓGICOS}

Este trabalho é orientado pelos pressupostos teóricometodológicos da Sociolinguística quantitativa ou modelo 
laboviano e pela perspectiva funcionalista de análise da língua, os quais pressupõem a não existência de estudos linguísticos desvinculados de fatores sociais, discursivos e contextuais e/ou estilísticos. Para a coleta dos dados e constituição do corpus, adotou-se a proposta de Eckert (2012), da terceira onda de estudos da variação e mudança linguística, a qual se volta para a depreensão do significado social intrínseco às variáveis em estudo. Dessa forma, nesta pesquisa focou-se a coleta de dados nas comunidades de prática "profissiões" tendo em vista a apreensão, no cerne das atividades e interações profissionais desenvolvidas pelos sujeitos falantes, a correlação entre o grau de proximidade/ intimidade (solidariedade) e distanciamento (poder) estabelecida durante as relações sociais, e como tais relações influenciam na escolha das formas de referência à segunda pessoa pelo sujeito. Portanto, compreendamos comunidades de prática como grupos de pessoas que compartilham uma preocupação ou uma paixão por algo que eles fazem e aprendem a fazê-lo melhor, a partir da interação regular e dos interesses em comum que possuem, no interior de uma atividade que a comunidade compartilha.

Esta coleta deu-se por meio da técnica de grupo focal, de comunidades de prática $^{11}$, e, por isso, nem sempre

11 Mas diferente da coleta de dados realizada por Freitag (2014), que se deu apenas em um 
delimitamos somente um tipo de rede social, haja vista que nosso interesse voltava-se para o profissional de maior status dentro daquela comunidade de prática e para a relação deste com os outros participantes, o que poderia ser manifestada pelo uso de tu, você e o(a) senhor(a). A partir do informante-base, escolhíamos os outros participantes de acordo com as características sociais de interesse neste estudo, e as relações sociais que mantinham com aquele.

Os eventos de fala que constituíram o corpus para análise foram obtidos por meio de 16 gravações de situações interacionais, em cada uma dessas situações comunicativas face a face, contamos com a participação de um grupo focal $^{12}$ constituído por 04 sujeitos-informantes, sendo que um, dentre os quatro, foi o nosso informante-base. Temos, portanto, 16 sujeitos-informantes-base, interagindo cada um com mais três interlocutores, o que corresponde a mais 48 sujeitos informantes, todos também cametaenses,

tipo de rede social de relacionamento pessoal existente dentro de uma comunidade de prática, a coleta dos dados de nossa pesquisa deu-se por meio da técnica de grupo focal, de comunidades de prática, e, por isso, nem sempre delimitamos somente um tipo de rede social, haja vista que nosso interesse voltava-se para o profissional de maior status dentro daquela comunidade de prática e para a relação deste com os outros participantes, o que poderia ser manifestada pelo uso de tu, você e o(a) senhor(a). A partir do informante-base, escolhíamos os outros participantes de acordo com as características sociais de interesse e as relações sociais que mantinham com aquele. Sem afastar-se, é claro, do seio da comunidade de prática analisada: funcionários de banco, comunidade escolar, grupo familiar, companheiros de política etc.

12 Nosso objetivo, ao adotarmos como opção metodológica, para este trabalho, o método de coleta de dados por meio do Grupo Focal, adveio da necessidade de obtermos trechos de fala resultantes de interação face a face entre os sujeitos e que tais trechos explicitassem, pelo uso de tu, você e o(a) senhor(a), as relações simétricas e assimétricas existentes entre estes participantes do grupo. 
totalizando 64 sujeitos interactantes envolvidos na amostra. Estes 16 sujeitos que participaram da pesquisa foram estratificados de acordo com faixa etária (08 na faixa etária I - 21 a 29 anos e 08 na faixa etária II - 32 a 42 anos); escolaridade (08 informantes com Ensino Médio e 08 com Ensino Superior); e sexo (08 do sexo masculino e 08 do sexo feminino).

O interesse, portanto, em adotar o grupo focal não é o aprofundamento de uma ideia ou tema específico a ser analisado a posteriori, já que trabalhamos com alternância pronominal, mas simplesmente a necessidade de se obter, em maior frequência, o uso de tais pronomes em interação face a face, contando que todas "as informações trazidas pelo participante podem ser identificadas como dados do grupo" (ANTONI et al, 2001, p.41). E quatro pessoas discutindo sobre um dado tópico em particular poderia gerar, em uma mesma interação, levantamento de dados bastante produtivo, o que dificilmente iríamos obter.

O critério para a seleção dos informantes-base que compuseram a amostra não foi aleatório e nem subjetivo, mas sim orientado por uma enquete realizada com os moradores da zona urbana do município de Cametá, através de duas formas de coleta $^{13}$ de opiniões: a primeira se deu

13 A enquete tanto pelo FACEBOOK como por via impressa possuía a mesma estrutura. 
por meio do site de relacionamento facebook $^{14}$ e a segunda por meio de um questionário impresso ${ }^{15}$. Assim, os dezesseis informantes-base deste estudo foram escolhidos na e pela comunidade investigada pelo seu nível de significância e status social adquiridos pela profissão que exercem ${ }^{16}$.

E a escolha dos outros três interlocutores de cada grupo focal se deu a partir de uma rede de relações sociais e profissionais entre eles e o informante-base, em conformidade com os princípios da semântica do poder "mais velho que", "pais do", "empregador do", "mais rico do que", "mais forte do que", e "mais nobre do que" ou " "mais poderoso do que" [e desconhecido do] e semântica da solidariedade - "participou da mesma escola [amigos, colegas, casados]" ou "têm os mesmos pais" ou "exercem a mesma profissão (BROWN; GILMAN, 1960, p.257- 258).

14 Todos os participantes eram pertencentes a minha rede de relacionamento e não houve o critério de estratificação social.

15 Àquelas que não possuem ou que muito pouco acessam facebook. No geral, para as duas formas de enquete, convidamos mais de 250 pessoas a participarem da pesquisa, mas recebemos a enquete respondida apenas por 136 pessoas, incluindo tanto a pesquisa pelo facebook - a de maior representatividade, como a do questionário impresso. Na enquete, perguntávamos, primeiro, qual o profissional de maior status social no município de Cametá e, em seguida, o porquê da escolha daquele profissional (se foi o fator financeiro ou o nível de importância social para Cametá).

16 Pensamos assim por acreditar que tais pessoas, principalmente os mais jovens, relacionam-se intensamente nos mais diferentes grupos e redes sociais, com carga de liderança bastante significativa na comunidade em que atuam e, no geral, não são conformistas, reagem aos valores sociais de sua realidade, e, consequentemente, podem transferir estes traços de não-conformidade para a linguagem. Então é preciso que olhemos mais detalhadamente para o indivíduo falante, o qual de acordo com Labov (2001, p.34 - tradução nossa) só poderá ser "entendido como o produto de uma história social única e na intersecção dos padrões linguísticos de todos os grupos sociais e categorias que definem esse indivíduo. 
Dessa forma, configurou-se o grupo focal: informante-base; interlocutor de relação assimétrica superior (manifestando poder sobre o informante-base); interlocutor de relação assimétrica inferior (o informante-base manifestando poder sobre este) e interlocutor de relação simétrica (informantebase e interlocutor mantendo relações solidárias).

Os traços sociais e as relações profissionais e/ou pessoais dos sujeitos-informantes participantes da pesquisa foram definidos intencionalmente com o objetivo de observarmos se há diferenciação ou não na forma de referência e estilo de fala empregada ao outro, e se isto é decorrente do status do interlocutor ou da relação social mantida com este, instituída não somente durante a conversação, mas na comunidade cametaense. Assim, refinamos a abrangência do foco de nossa análise, para grupos sociais mais específicos de fala, com o intuito de atentarmos, por meio de interações sociais simétricas e assimétricas, se de fato estamos diante de sujeitos falantes com traços de líderes ${ }^{17}$ da mudança linguística. Analisar, portanto, tipos sociais com alto nível de interação em diferentes redes sociais foi-nos oportuno,

17 A seleção dos participantes foi pensada em conformidade com Labov (2001), que concluiu, na busca pelos líderes da mudança, nos bairros da Filadélfia, que existiam pessoas destas comunidades locais que ocupavam uma posição central nas redes de relações sociais da vizinhança. Porém, para Labov (2001), esta centralidade não abrangia o elevado status social e o aspecto da hierarquia socioeconômica do líder da mudança, mas principalmente seu prestígio local, assim como a atividade de trabalho exercida por ele e a interação verbal com outros grupos, que não necessariamente pertencentiam ao seu bairro de origem. 
porque nos permitiu observá-los falando com pessoas com as quais geralmente falam no dia-a-dia, como amigos, familiares, colegas de trabalho e/ou funcionários. Então se há mudança em progresso, esta é resultado não do isolamento dos sujeitos em redes sociais mais densas e sim das diversas ligações diárias com outros sujeitos dos mais diferentes níveis sociais.

Os dados que compuseram o corpus desta pesquisa foram analisados pelo programa computacional GOLDVARB. A predileção, da base quantitativa de análise, incluindo a definição das variáveis independentes, tomadas como categorias de análise, parte do pressuposto de que as produções linguísticas do falante demonstram uma distribuição probabilística das variantes, em que uma pode ocorrer mais em um dado contexto e menos em outro, ou até mesmo nunca ocorrer em um dado contexto.

\section{OS PRESSUPOSTOS FUNCIONALISTAS - O PRINCÍPIO DA MARCAÇÃO EM ANÁLISE}

Com base nos pressupostos teóricos do Funcionalismo, atrelados à noção de variação da sociolinguística laboviana, pretendemos examinar restrições funcionais presentes na alternância entre tu/você/o(a)/senhor(a). De um total de 64 informantes, obtivemos 527 ocorrências de pronomes de 
segunda pessoa do singular tu, você e o(a) senhor(a), sendo 307 dados de $t u$, correspondendo a $58.3 \%$ da amostra, 182 dados de você, correspondendo a $34.5 \%$ da amostra e 38 dados de o(a) senhor(a), correspondendo a 7.2\% dos dados da amostra, conforme tabela 01.

\begin{tabular}{l|c|c}
\hline \hline \multicolumn{1}{c|}{$\begin{array}{c}\text { Forma pronominal de referência à } \\
\text { segunda pessoa na função de sujeito }\end{array}$} & Frequência & Total De Dados \\
\hline TU & $58.3 \%$ & 307 \\
\hline VOCÊ & $34.5 \%$ & 182 \\
O(A) SENHOR(A) & $7.2 \%$ & 38 \\
\hline \hline \multicolumn{2}{l}{ TOTAL DE DADOS } & 527 \\
\hline \hline
\end{tabular}

Tabela 01 - Frequência de ocorrência das formas pronominais de segunda pessoa no português falado na zona urbana do município de Cametá (PA). (Fonte: própria)

Diante dos dados estatísticos, chegamos a um primeiro resultado desta interface, derivado do uso da forma tu como a forma menos marcada considerando o subprincípio da distribuição de frequência. Segundo este subprincípio formas linguísticas marcadas tendem a ser menos frequentes do que as não-marcadas (GIVÓN, 1993). Portanto, o pronome tu, ao apresentar maior expressividade de uso, 58.3\% na rodada geral tu/você/o(a)/senhor(a).

Corrobora este o subprincípio da complexidade estrutural já que a forma tu é a menor. Poderíamos inferir, ao que tudo indica, pela recorrência significativa de tu, em contextos como de estruturas paralelas tu-tu e tipo de referência específica direta e indireta a um interlocutor, categorias consideradas de menor complexidade cognitiva, que este pronome atua 
em contextos gramaticais de menor complexidade cognitiva, por tais estruturas não exigirem tanto esforço mental, atenção e tempo de processamento das informações.

Nesse sentido, verificamos que o uso de tu, na zona urbana de Cametá, é menos marcado, pela correlação dos três subprincípios de marcação de base funcionalista, preconizados por Givón (1995): alta frequência, menor complexidade estrutural e cognitiva. Isto confirma a pressuposição do autor de que há uma relação icônica entre a informação linguística e a maneira como é representada na estrutura linguística, durante o evento comunicativo.

Logo, existe um isomorfismo entre forma e função na língua. Nossos resultados para o pronome tu atestam a atuação do princípio da marcação: a forma menos marcada ocorre em estruturas menos marcadas. Conforme Givón (1995, p.58 grifos do autor), pelo meta-princípio de marcação "categorias que são cognitivamente mais marcadas (isto é, complexas) tendem também a ser estruturalmente marcadas ${ }^{18 "}$.

Das 38 ocorrências de $o(a)$ senhor existentes no corpus, todas foram usadas em contextos de assimetria - de inferior para superior, o que reforça, ainda mais, os traços de estilo formal atrelado a tal variante. Desta forma, concebemos que o uso de um estilo mais formal pode estar atrelado às relações mais

18 Categories that are cognitively marked - i.e. complex - tend also to be structurally marked. 
assimétricas e o uso do estilo menos formal, às relações mais simétricas. Então, o falante acomoda a sua fala aos traços do seu interlocutor, em uma tentativa de igualar a sua performance linguística ao status social e variedade que ele possui. Logo, a variação intrafalante existe em função da variação dos traços sociais dos interlocutores.

De acordo com Labov (2001), as variantes alternam-se nas comunidades à proporção que os estilos de fala também se alteram. A mudança de estilo ocorre porque os papéis e os status sociais dos interlocutores, assumidos durante o processo interativo, sofrem transformações (BELL, 1984). Portanto, tu, forma menos marcada, é mais propício a situações de menor formalidade evocê eo(a) senhor(a), pronomes de distanciamento maior entre locutor e interlocutor, consequentemente mais formais, são mais marcados.

E a partir dos dados obtidos na tabela 01, refinamos a análise, agora somente atentando para as variantes tu versus você e levantamos um total de 489 ocorrências, sendo 307 da forma pronominal tu, e 182 do pronome de tratamento você, observado aqui como pronome de segunda pessoa do discurso, o que corresponde, respectivamente, a 62.2\%, e $37.8 \%$ de percentual dos dados considerados na pesquisa. Na tabela abaixo, apresentamos as variantes, a porcentagem referente a cada uma das variantes e o valor total dos dados 
de nossa pesquisa. Seguem-se à tabela 02, exemplos das formas sob análise.

\begin{tabular}{r|c|c}
\hline $\begin{array}{c}\text { Forma pronominal de referência à } \\
\text { segunda pessoa na funcão de suieito }\end{array}$ & Aplicação/ Total & Percentagem \\
\hline TU & 307 & $62.8 \%$ \\
\hline VOCÊ & 182 & $37.2 \%$ \\
\hline Total dos dados & 489 & $100 \%$ \\
\hline
\end{tabular}

Tabela 02 - Frequência de ocorrência das formas pronominais de segunda pessoa - tu versus você no português falado na zona urbana do município de Cametá (PA). (Fonte: própria)

Tais resultados reafirmam nossa hipótese geral de que a forma pronominal tu é a mais corrente, como forma canônica de segunda pessoa, na linguagem oral dos falantes da zona urbana de Cametá. E por meio do peso relativo, podemos deduzir que não está sendo substituída por você, nesta variedade linguística, do Norte do Brasil, muito embora, neste estado sincrônico da língua, coexistam funcionalmente como pronome em referência à pessoa com quem se fala.

A partir de agora olharemos para os fatores elencados pelo programa Goldvarb como os favorecedores da aplicação da regra variável em análise. Examinaremos, também, a validação ou não das hipóteses levantadas para a exploração do fenômeno em estudo bem como a atuação do princípio da marcação.

\subsection{Paralelismo estrutural/linguístico}

Tomado o fator paralelismo estrutural/linguístico, selecionado como primeiro grupo de fatores estatisticamente 
significativo à realização de tu, observamos em comunhão às ideias de Givón (1995), que determinadas estruturas gramaticais, como as paralelas, possuem relação motivada entre a organização da gramática e os conceitos que esta representa consoante as necessidades ou intenções comunicativas do falante, pois, um emprego como primeiro item da série da forma tu na estrutura frasal, irá atrair significativamente, nas orações seguintes, o uso repetido desta mesma forma, como os resultados atestaram para estruturas paralelas tu-tu, elevada frequência, $92 \%$ e significância 0,854, o que as tornam de menor complexidade cognitiva por codificarem explicitamente repetidas vezes a mesma informação. Então, um uso primeiro do tu ativará, na fala, a recorrência desse termo em estruturas seguintes.

\begin{tabular}{l|c|c|c}
\hline \multicolumn{1}{c|}{ Paralelismo estrutural } & Aplicação/ total & Percentagem & Peso relativo \\
\hline $\begin{array}{l}\text { Não primeiro da série, } \\
\text { precedido por tu-tu-tu }\end{array}$ & $195 / 212$ & $92 \%$ & 0,854 \\
\hline $\begin{array}{l}\text { Não precedido de forma } \\
\text { pronominal, isolado na } \\
\text { oração }\end{array}$ & $42 / 69$ & $60.9 \%$ & 0,387 \\
\hline $\begin{array}{l}\text { Primeiro item da série, } \\
\text { não precedido de forma } \\
\text { pronominal }\end{array}$ & $51 / 86$ & $59.3 \%$ & 0,387 \\
\hline $\begin{array}{l}\text { Não primeiro da série, } \\
\text { precedido por você }\end{array}$ & $18 / 117$ & $15.4 \%$ & 0,077 \\
\hline $\begin{array}{l}\text { Não primeiro da série, } \\
\text { precedido por o(a) senhor(a) }\end{array}$ & $1 / 5$ & $20 \%$ & 0,067 \\
\hline \begin{tabular}{l} 
Total dos dados \\
\hline
\end{tabular}
\end{tabular}

Tabela 03 - Atuação do paralelismo estrutural no uso tu versus você do português falado na zona urbana do município de Cametá (PA). (Fonte: própria) 
Neste sentido, as categorias linguísticas que possuem funções muito próximas, ou como no caso de tu, uma mesma função, serão dispostas, com maior proximidade no discurso, tendo em vista, cognitivamente, tornar o contexto de fala menos opaco e agilizar o seu processamento, seja este do ponto de vista da produção quanto da compreensão. Logo, um pronome menos marcado favorecerá este mesmo pronome subsequente, igualmente menos marcado. Então, no geral, o falante que usa o pronome $t u$, continua usando-o na fala nos enunciados seguintes, atendendo uma tendência natural da língua de normas gramaticais semelhantes ocorrerem juntas.

O que parece constituir menor esforço cognitivo, redundância, automatismo, menor densidade semântica, acaba sendo ignorado pelo falante, quando tudo isto contribui, em nível interacional e discursivo, para o falante atingir o propósito comunicativo dele, o de tornar a compreensão do dito mais eficiente, o processamento da informação mais rápido e uma maior interconexão entre os interlocutores, consequentemente gerando maior carga informacional para o período, que por sua vez constitui significado para o discurso.

\subsection{Tipo de interlocução/referência}

Da mesma forma, podemos constatar a atuação do 
princípio da marcação com o grupo de fatores Tipo de interlocução/referência, que apontou a forma tu como mais frequente em referência indireta e direta a um indivíduo, com peso relativo de 0,849 e 0,688 respectivamente de acordo com tabela 04, referências estas que conceituamos, pela adoção do princípio de marcação de Givón (1995), como não marcadas, por fazerem alusão a um interlocutor de existência real, presente ou não no evento comunicativo, a quem se está referenciando, o que parece tornar o contexto comunicativo menos complexo, logo de menor complexidade cognitiva.

\begin{tabular}{ccccc}
\hline Referência do pronome & Aplicação/ total & Percentagem & Peso relativo \\
\hline $\begin{array}{c}\text { Referência indireta/ } \\
\text { específica a um indivíduo' }\end{array}$ & $66 / 94$ & $70.2 \%$ & 0,849 \\
$\quad$ Referência direta/ & $59 / 81$ & $72.8 \%$ & 0.688 \\
$\begin{array}{c}\text { específica a um indivíduo } \\
\text { Referência ao próprio } \\
\quad \text { falante" }\end{array}$ & $25 / 38$ & $65.8 \%$ & 0.364 \\
$\begin{array}{c}\text { Referência genérica"l' } \\
\text { Referência indireta a um }\end{array}$ & $16 / 21$ & $76.2 \%$ & 0.338 \\
$\quad$ grupo & $140 / 244$ & $57.4 \%$ & 0,320 \\
\hline \hline Total dos dados & $307 / 489$ & & \\
\hline
\end{tabular}

Tabela 04 - Tipo de interlocução/referência do pronome na rodada binária Tu versus você/o(a) senhor(a). (Fonte: própria)19

19 Notas da Tabela - I. Consideramos a referência indireta a um indivíduo como aquela mencionada pelo falante, por meio do discurso relatado, na qual a segunda pessoa pode ou não ser reconhecida pelos participantes do quadro comunicativo, constituindo-se apenas de existência específica e referencial no mundo discursivo; II. Ocorre quando a segunda pessoa do discurso a quem o falante se refere é o próprio falante; III. Evento de fala no qual o uso do pronome de segunda pessoa é remetido a outro quadro interativo ou frame, não dirigido a um interlocutor específico ou a um grupo socialmente definido, reconhecido, presente ou não no curso da situação de fala; IV. É denotada como aquela direcionada a um interlocutor, que não é singular, único, em termos de especificidade pessoal, mas sim um grupo, que encapsula os interlocutores tornando-os comuns, por meio de alguns traços sociais, tais como: a mesma profissão (professores, bancários, políticos, estudantes universitários), moradores do mesmo bairro, cidade ou país, possuidores do mesmo nível social ou de escolaridade, etc. 
Isso reforça o pensamento givoniano de que categorias menos, ou mais marcadas cognitivamente, tendem a ser estruturalmente menos ou mais marcadas. Portanto, o falante opta pelo pronome tu, que, em relação a você e o(a) senhor(a), é tido como menos marcado, pois estruturas não marcadas atraem formas não marcadas. Enquanto que você, pronome marcado, é frequente na referência genérica, cujo interlocutor não é de conhecimento especificado e/ou determinado pelo falante, comprovado pelo peso relativo de 0,680 para a referência genérica para um grupo e 0,662 para a referência genérica (na rodada você versus $t u$ ).

O uso deste tipo de discurso, ao que tudo orienta, tende a particularizar tais construções linguísticas com este tipo de forma pronominal. Então poderíamos associar o fato de o pronome $t u$, menos marcado na comunidade em estudo, ser favorecido por estes contextos discursivos de referência, que acreditamos compartilhar deste mesmo princípio de marcação, ou seja, constituir traço não marcado.

\section{3 TIPO DE FRASE}

Outro contexto de aplicação do meta-princípio de marcação (GIVÓN, 1995), observado pelos dados percentuais obtidos nesta pesquisa, é o tipo de frase/entonação negativa 
favorecendo o emprego da forma você ${ }^{20}$ com 0,685 de peso relativo e $47,1 \%$ de percentual. Se frases negativa e interrogativa são classificadas como mais marcadas, por serem menos frequentes na língua e apresentarem maior amplitude na estrutura oracional, justificamos então o emprego significativo da forma você no tipo frasal declarativo negativo, enquanto a frase declarativa afirmativa é não marcada nas línguas naturais, por ser mais frequente.

As sentenças negativas são tidas como marcadas não somente pelo subprincípio da distribuição de frequência, já que menos frequentes, mas também pelo princípio da complexidade estrutural e cognitiva, pois, em comparação às exclamativas, interrogativas e declarativas, têm maior extensão fônica, resultante do acréscimo da partícula negativa. Quanto à complexidade cognitiva, vemos, assim como Othero (2007), que as sentenças negativas sempre pressupõem uma sentença afirmativa. Então, se de fato há sempre pressuposição nas frases negativas, logo são cognitivamente mais complexas.

\begin{tabular}{|c|c|c|c|}
\hline Tipo de frase & Aplicação/Total & Percentagem & Peso Relativo \\
\hline Exclamativa & $16 / 20$ & $80 \%$ & 0,882 \\
\hline $\begin{array}{l}\text { Interrogativa (negativa e } \\
\text { afirmativa) }\end{array}$ & $28 / 43$ & $65.1 \%$ & 0,596 \\
\hline $\begin{array}{l}\text { Declarativa Afirmativa } \\
\text { Declarativa Negativa }\end{array}$ & $\begin{array}{c}236 / 375 \\
27 / 51\end{array}$ & $\begin{array}{l}62.9 \% \\
52.9 \% \\
\end{array}$ & $\begin{array}{l}0,488 \\
0,315\end{array}$ \\
\hline Total de dados & $307 / 489$ & & \\
\hline
\end{tabular}

20 Rodamos, para obtenção deste valor, você versus tu (valor de aplicação você). 
Tabela 05 - Tipo de Frase na rodada binária Tu versus você do português falado na zona urbana do município de Cametá (PA). (Fonte: própria)

Se frases negativa e interrogativa são classificadas como mais marcadas, por serem menos frequentes na língua e apresentarem maior amplitude na estrutura oracional, justificamos então o emprego significativo da forma você no tipo frasal declarativo negativo, enquanto a frase declarativa afirmativa é não marcada nas línguas naturais, por ser mais frequente.

As sentenças negativas são tidas como marcadas não somente pelo subprincípio da distribuição de frequência, já que menos frequentes, mas também pelo princípio da complexidade estrutural e cognitiva, pois, em comparação às exclamativas, interrogativas e declarativas, têm maior extensão fônica, resultante do acréscimo da partícula negativa. Quanto à complexidade cognitiva, vemos, assim como Othero (2007), que as sentenças negativas sempre pressupõem uma sentença afirmativa. Então, se, de fato, há sempre pressuposição nas frases negativas, logo são cognitivamente mais complexas.

De acordo com os resultados, há mais probabilidade da forma tu ocorrer em frases exclamativas e interrogativas do que nas declarativas. Acreditamos que este fato seja reflexo de dois fatores: da situação interacional de coleta dos dados, na qual os participantes demonstravam-se à vontade 
para interrogar e exclamar algum fato ou situação ao seu interactante e até mesmo ao pesquisador/moderador, no decorrer da interação, e da situação conversacional, já que, semanticamente, tu representa o pronome usado nas relações de maior igualdade, envolvendo a semântica da solidariedade, sendo, portanto, a forma escolhida pelo falante para ser empregada quando há maior interação face a face. Isso acontece, porque, em enunciados do tipo "pergunta", a interação comunicativa requer a presença mais específica de um interlocutor - eu-tu a quem se dirige a admiração, exclamação, surpresa, ênfase a aquilo que se diz ou questionamento, o que torna a relação comunicativa mais próxima entre falante/ouvinte, e como a forma tu é a mais usual e não parece denotar distanciamento social, acaba sendo mais frequente para este tipo de frase.

Esta forma de conceber os dados é intensificada ainda mais quando olhamos para os fatores declarativa afirmativa e declarativa negativa, os quais desfavoreceram a forma tu e automaticamente favoreceram a você $\hat{e}^{21}$. O tipo afirmativo, com 236 dos 376 ocorrências encontradas no corpus é o fator de maior frequência estatística do grupo. Isto leva-nos

21 Este grupo de fatores, na rodada entre você versus tu (valor de aplicação - você), foi selecionado para a explicar a ocorrência de você e os fatores selecionados entre os mais significativos do grupo, constituíram aqueles que na rodada entre tu versus você desfavorecem à aplicação de tu: declarativa afirmativa e declarativa negativa, com pesos relativos de $0,514 \mathrm{e}$ 0,679 , respectivamente. 
a perceber que, em frases do tipo [62], quando a referência a um interlocutor é genérica, o falante dá preferência pela variante você, pois essa forma pronominal é preferida em situações interativas em que não há a presença de um interlocutor definido, e o discurso declarativo pode ser dirigido a mais de uma pessoa, um coletivo e não a um interlocutor definido, como o defendido pela nossa hipótese corroborada pelos dados.

\subsection{Tipo de relação entre os interlocutores}

Outro dado que contribui para tomarmos a forma tu como não marcada, diz respeito à variação estilística. Como mencionamos anteriormente, os pronomes se diferenciam quanto ao nível de formalidade e informalidade discursiva, e a forma tu é geralmente empregada em relações interpessoais mais simétricas, tomado como pronome de maior informalidade diante de você e o(a) senhor(a). E os dados revelaram que o emprego do pronome tu é mais recorrente nas interações simétricas (colegas de classe ou de mesma profissão e/ou trabalho, irmãos, amigos, pessoas da mesma idade, ou que possuem um mesmo status social) com percentual de $65.6 \%$ e $\mathbf{0 , 6 0 3}$ de peso relativo, como se pode notar na tabela 06 , abaixo:

\begin{tabular}{c|c|c|c}
\hline \hline $\begin{array}{c}\text { Tipo de relação entre os } \\
\text { interlocutores }\end{array}$ & Aplicação/Total & Percentagem & Peso Relativo \\
\hline \hline
\end{tabular}




\begin{tabular}{lccc}
\hline Assimétrica 01 (de inferior & $246 / 375$ & $65.6 \%$ & 0,603 \\
$\begin{array}{l}\text { para superior) } \\
\text { Assimétrica 02 (de superior }\end{array}$ & $48 / 86$ & $55.5 \%$ & 0,246 \\
$\begin{array}{l}\text { para inferior) } \\
\text { Simétrica }\end{array} \quad \begin{array}{ll}\text { Total dos dados } \\
\quad 307 / 489\end{array}$ & $46.4 \%$ & 0,104
\end{tabular}

Tabela 06 - Tipo de relação entre os interlocutores na rodada binária Tu versus você do português falado na zona urbana do município de Cametá (PA). (Fonte: própria)

Tal fato aproxima-se do postulado de Givón (1995) de que o princípio de marcação não remete apenas às categorias linguísticas, podendo ser aplicado também aos diferentes registros da língua. Neste sentido, o autor considera a linguagem formal como sendo mais marcada do que a informal, na medida em que possui maior complexidade cognitiva de processamento do que esta. Acreditamos também que contextos menos formais devido à existência de relações mais solidárias são menos marcados que contextos mais formais.

No trecho da interação abaixo, observa-se a utilização dos pronomes tu entre pessoas de mesmo status social ou que possuam alguma relação de intimidade entre si, como uma conversa entre amigos, no caso do exemplo [01] entre pessoas de mesmo status social considerados pela sociedade pelas pessoas da comunidade.

[01] até mesmo nas lojas quando a gente vai comprar ... antes quando ninguém conhecia ... a gente não podia comprar fiado ... hoje em dia não leva aí tu pode tu pode depois a gente ver [relação íntima - entre amigos/conhecidos] 
No trecho [01] acima, observamos que o pronome tu, é usado por um professor, em referência direta a outro professor, colega de trabalho, há muito tempo, com o qual mantém relações de maior proximidade socialmente. Este emprego reforça ainda mais a função solidária semântico-discursiva do pronome nas relações sociais simétricas, isto é, entre pessoas que desempenham os mesmos papeis sociais no ato discursivo.

O interessante dos nossos dados são os resultados para a relação assimétrica 02 (de superior para inferior), o uso de tu neste tipo de relação é pouco produtivo, com peso relativo de 0,246 , reforçando ainda mais, através do uso, a forma tu como um pronome que marca as relações solidárias e não de poder, seja esta de inferior para superior ou de superior para inferior. Logo, inferimos, a partir de tais achados, que as relações assimétricas inibem o uso de tu na fala pesquisada, conforme exemplo [02], em que temos um diálogo tecido entre um falante/estudante universitário e seu interlocutor/ aluna do ensino médio, o que, consequentemente, levanos a perceber uso funcional e discursivo destas formas de referência à segunda pessoa, ainda com nuances diferenciais na comunicação.

[02] Débora ... você ouvindo tudo isso que eles falam sobre a profissão do professor ... você um dia pensa em seguir essa carreira (professor/aluno). 
Tais usos, constata-se pelo grupo de fatores Tipo de relação entre os interlocutores, demonstram que há significação social no contexto discursivo de uso destes pronomes, advindos das próprias relações de solidariedade ou diferenciação social entre os participantes do processo comunicativo. $\mathrm{O}$ que podemos abstrair da variação desses pronomes é que possuem contextos de uso diferenciados e por isso significativos, sendo que o tu é mais atuante em contextos de simetria social e o você, em relações assimétricas. O desfavorecimento de tu ainda é mais significativo em nossa pesquisa quando o falante o emprega em referência a um interlocutor de status social superior, com percentual de $46.4 \%$ e peso relativo de 0,104 , decaindo significativamente do valor neutro da regra de aplicação do peso de significância, pois neste tipo de relação assimétrica é muito pouco produtivo na comunidade em análise, se compararmos ao mesmo uso desta forma em função das relações simétricas e assimétricas 02 , reforçando ainda mais, através do uso, a forma tu como um pronome de solidariedade, o que acreditamos ser reflexo de um estabelecimento proposital de definição bem segmentada e diferenciada de classes sociais distintas.

Então o não uso de tu, tido aqui como marca de solidariedade e igualdade, pelo falante que se considera, 
dentro de uma hierarquia social estabelecida durante a interação, em nível de status abaixo de seu interlocutor, pode marcar o reconhecimento da não reciprocidade de poder entre falante e interlocutor, o que demonstra que ambos não podem exercer o mesmo poder sobre o outro. Tal dado em relação à variação estilística contribui para tomarmos a forma tu, como não marcada. Como mencionamos anteriormente, os pronomes se diferenciam quanto ao nível de formalidade e informalidade discursiva, e a forma tu é geralmente empregada em relações interpessoais mais simétricas, tomado como pronome de maior informalidade diante de você e o(a) senhor(a).

Este resultado aproxima-se do postulado de Givón (1995) de que o princípio de marcação não remete apenas às categorias linguísticas, podendo ser aplicado também aos diferentes registros da língua. Neste sentido, o autor considera a linguagem formal como sendo mais marcada do que a informal, na medida em que possui maior complexidade cognitiva de processamento do que esta. Acreditamos também que contextos menos formais, devido à atuação de relações mais solidárias são menos marcados que contextos mais formais. Portanto, tu, forma menos marcada, é mais propício a situações de menor formalidade e você e o(a) senhor(a), pronomes de distanciamento maior entre locutor 
e interlocutor, consequentemente mais formais, são mais marcados.

Desta forma, concebemos que o uso de um estilo mais formal pode estar atrelado às relações mais assimétricas e o uso do estilo menos formal, às relações mais simétricas. Por isso, consideramos, de acordo com nossos resultados, que a manifestação de diferentes variantes de acordo com o nível de formalidade e informalidade é conduzida pelo menor ou maior grau de proximidade entre os falantes. E esta relação é definida a partir do status que estes possuem durante a situação de fala. Por outro lado, o uso da forma "você" indica também que pode estar havendo uma tendência a igualar ou tornar as relações sociais menos desiguais, já que parece que você carrega mais traços interacionais de polidez e de cortesia.

\section{CONSIDERAÇÕES FINAIS}

Nesta pesquisa, procuramos descrever e analisar as formas de referência à segunda pessoa, em função de sujeito, usadas na linguagem oral dos falantes da cidade de Cametá-PA. Na rodada, tu versus você, os fatores significantes considerados nesta análise foram 03 (três) linguísticos/discursivos (internos) - paralelismo estrutural, referência do pronome e tipo de frase/entonação - e 01 (um) social ou extralinguístico 
- tipo de relação entre os interlocutores.

O objetivo, portanto, era obervar a correlação entre a frequência de uso de tu/você os princípios de marcação de Givón (1993), e aplicando tal princípio à frequência de uso de tais pronomes, concluímos que o pronome $t u$, em contextos de competição com você/o(a) senhor(a), caracteriza-se como forma menos marcada do que estas, pois pelo princípio de distribuição de frequência é mais frequente que você/o(a) senhor(a), atestado na rodada geral $t u / v o c e ̂ / o(a)$ senhor(a), $58.3 \%$ (tu), 34.5\% (você) e 7.2\% (o(a) senhor(a)).

Verificamos que o uso de $t u$, na zona urbana de Cametá, é menos marcado, pela correlação dos três subprincípios de marcação de base funcionalista, preconizados por Givón (1995): alta frequência, menor complexidade estrutural e cognitiva. Isto confirma a pressuposição do autor de que há uma relação icônica entre a informação linguística e a maneira como é representada na estrutura linguística, durante o evento comunicativo. Logo, existe um isomorfismo entre forma e função na língua. Nossos resultados para o pronome tu atestam a atuação do princípio da marcação: a forma menos marcada ocorre em estruturas menos marcadas. Conforme Givón (1995, p.58 - grifos do autor), pelo metaprincípio de marcação "categorias que são cognitivamente mais marcadas (isto é, complexas) tendem também a ser 


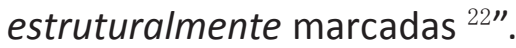

A forma você apresenta-se mais regular em contextos como: referência genérica a um interlocutor e referência genérica a um grupo e em frase/entonação negativa, contextos estruturalmente marcados, pela menor frequência na fala e maior complexidade cognitiva e estrutural de compreensão. De forma semelhante também ocorre com a forma $o(a)$ senhor(a), mais constante em frases do tipo interrogativa e negativa e em contextos discursivos de fala reportada e/ou discurso indireto relatado, construções estas, estruturalmente complexas.

Nesta pesquisa optamos pelo estudo das formas de segunda pessoa tu, você, o(a) senhor(a), a partir de dados oriundos da interação entre informante-base e mais três interlocutores, em grupos focais que representam uma comunidade de prática de cunho profissional. Aspirávamos verificar nesta, pelo prisma das relações semânticas de poder e solidariedade, o uso diferenciado destes pronomes, e como estas relações sociopessoais interfeririam na variação estilística, a nível de formalidade e informalidade do discurso. E claro, esta foi uma decisão teórico-metodológica, que atendia aos objetivos da pesquisa. Porém, esta metodologia, pode avançar, em pesquisas posteriores, para a coleta

22 Categories that are cognitively marked - i.e. complex - tend also to be structurally marked. 
de dados que não restrinja a percepção do uso de tais pronomes somente a uma rede de relações - a profissional, e sim a dinâmica interacional do falante, nas mais diversas situações comunicativas, em diferentes redes sociais de relacionamento, levando a perceber outras nuanças entre contextos formais e informais de comunicação. Assim como a análise das formas pronominais pode ser estendida a fala de todos(as) os membros participantes da interação, não somente de um interlocutor-informante-base, como o priorizado por esta pesquisa.

Outrossim, trabalhos futuros podem ampliar o estudo sobre a interferência das relações sociais no uso de $t u$, você e o(a) senhor(a), a partir da inclusão e aprofundamento das relações de intimidade/proximidade afetivas entre os interlocutores, já que neste, observamos somente relações sociais de poder e solidariedade instituídas na fala, por meio do status social dos falantes. Logo, o trabalho mais enfático com diferentes redes sociais pode suscitar novas descobertas de aplicabilidade destes pronomes na fala cametaense, diferentes dos achados por esta pesquisa. Acreditamos que tais desdobramentos, e até mesmo inquietações, motivem trabalhos posteriores no âmbito dos estudos sociolinguísticos variacionistas. E que os resultados desta pesquisa contribuam para a ampliação e caracterização das formas de referencia à 
segunda pessoa no Português Brasileiro.

\section{REFERÊNCIAS}

ANDRADE, Adriana Lília Soares de (2004). A variação você, ce, ocê no português brasileiro falado. (Dissertação - Mestrado em Linguística) Programa de Pós-graduação em Linguística, Universidade Federal de Brasília, Brasília.

BELL, Alan (1984). "Language style as audience design". In Language in Society. Cambridge Journals. 13 (2), 145-204, jun. In http://journals. cambridge.org Acesso em 02.Jun.2014.

CUNHA, Maria Angélica Furtado da; OLIVEIRA, Mariangela Rios de; MARTELLOTA, Eduardo (2003). (Orgs). Linguística Funcional: teoria e prática. Rio de Janeiro: DP \& A.

ECKERT, Penelope (2015). Three Waves of Variation Study: The emergence of meaning in the study of variation. Stanford University. In http://web. stanford.edu/ eckert/PDF/ThreeWavesofVariation.pdf. Acesso em 04.Jul.2015.

(1989 [1990]). "The whole woman: Sex and gender differences in variation". Language Variation and Change. Cambridge University Press 1, 245-267. In http://web.stanford.edu/ eckert/PDF/WholeWoman.pdf. Acesso em 04.Dez.2015.

FONTAINE, Jacqueline (1978). O círculo linguístico de Praga. João Pedro Mendes (Trad.). São Paulo: Cultrix: Ed. Da Universidade de São Paulo.

GIVÓN, Talmy (1990). Syntax: a Functional-Typological Introduction. 2. Amsterdam/Philadelphia: John Benjamins.

(1993). "Verbal Inflections: Tense, Aspect, Modality and Negation". In: English Grammar: a function-based introduction. I e II. Amsterdam/Philadelphia: John Benjamins Publishing Co.

(1995). Functionalism and grammar. John Benjamins Publishing Company. Amsterdam/Philadelphia.

HOPPER, Paul (1991). "On some principles of grammaticization". In: TRAUGOTT E.C.; HEINE B. (Eds). Approches to Grammaticalization. Amsterdam/ Philadélfia: John Benjamins Publishing Co. 
LABOV, William (1963). "The social motivation of a sound change". Word, n.19, p.273-309.

(2006 [1966]). The social stratification of English in New York City. Center for Applied Linguistics. 2.ed. Cambridge University Press, p.03-86.

(2001) "The anatomy of style shifting". In: ECKERT, Penelope; RICKFORD, John R. Style and Sociolinguistic Variation. Cambridge University Press, p.85-108.

LAVANDERA, Beatriz (1978). "Where does the sociolinguistic variable stop?" Language in Society, 7(2), August, 171-182.

MAY, Guilherme Henrique (2009). "Discutindo o papel do funcional no sociofuncionalismo". Work paper linguística, 10(2), 69-79, Florianópolis. In https://periódicos.ufsc.br/index.php/. Acesso em 16.Fev.2013.

MODESTO, Artarxerxes Tiago Tácito (2006). Formas de tratamento no português brasileiro: a alternância tu/você na cidade de Santos-SP. 2006. 151f. (Dissertação - Mestrado em Linguística) - Programa de Pósgraduação em Linguística, Universidade de São Paulo, São Paulo.

(2007) "Formas de tratamento no português brasileiro: a alternância tu / você na cidade de Santos-SP". Revista Letra Magna, 4(7). In http://www.letramagna.com. Acesso em 12.Dez.2015.

NEVES, Maria Helena de Moura (1997). A gramática funcional. São Paulo: Martins Fontes,.

OLIVEIRA, Luanda Almeida Figueiredo de (2007). Tu e Você no português popular do estado da Bahia. VIII Seminário de Pesquisa e Pós-Graduação da UFBA. Salvador.

OTHERO, Gabriel de Ávila (2007). "A negação nas línguas: um universal linguístico". Revista Eletrônica do Instituto de Humanidades. 6(23).

PIRES, R. de Oliveira (1999). “Uma história de delimitações teóricas: 30 anos de semântica no Brasil". D.E.L.T.A., 15, n. especial.

REIS, Mariléia Silva dos (2003). Atos de fala não-declarativos de comando na expressão do imperativo: a dimensão estilística da variação sob um olhar funcionalista. 212f. (Tese - Doutorado/Linguística). Florianópolis: UFSC. 
SANTOS, Viviane Maia dos (2010). "A constituição de corpora orais para a análise das formas de tratamento". Encontro do Círculo de Estudos Linguísticos do Sul, 9, Palhoça, SC.

WEINREICH, Uriel; LABOV, William; HERZOG, Marvin I (2006). Marcos Bagno (Trad.). Fundamentos empíricos para uma teoria da mudança linguística. São Paulo: Parábola.

Raquel Maria da Silva Costa é Professora Adjunto I da Faculdade de Linguagem da Universidade Federal do Pará/Campus Universitário do Tocantins/Cametá-Pará. Doutora em Linguística, linha de pesquisa: Descrição e Análise Linguística - Universidade Federal do Ceará (UFC) (2016). Mestra em Linguística, Linha de pesquisa: Análise, Descrição e Documentação do Português regional da Amazônia UFPA (2009). Especialista em Estudos Culturais da Amazônia - UFPA (2006). Graduada em Letras - Habilitação em Língua Portuguesa pela Universidade Federal do Par - UFPA (2004). Professora da cadeira de Linguística do Curso de Letras - Habilitação em Língua Portuguesa. Atua como pesquisadora do Projeto Vozes da Amazônia, coordenado pela UFPA, investigando e descrevendo o comportamento vocálico das médias em posição pretônica e postônica não-finais no português falado no município de Cametá, no qual está inserido o projeto que coordena "O sistema vocálico do português do Nordeste Paraense: caracterização acústica das vogais pretônicas". É membro do grupo SOCIOLIN-CE (Grupo de Pesquisas Sociolinguísticas), sediado e coordenado pela UFC, coordena o projeto de pesquisa "As formas de tratamento nominais e pronominais nas redes sociais em Cametá-PA". Possui experiência na área de Linguística, com ênfase em Sociolinguística e como professora de Língua Portuguesa e Língua Inglesa, no ensino fundamental e médio, no município de Cametá. 